\title{
Observatório Geográfico do Leste Metropolitano do Rio de Janeiro (OBGEO- LMRJ) do Departamento de Geografia da FFP/UERJ
}

\author{
Andrelino de Oliveira Campos \\ Professor Adjunto do Departamento de Geografia da FFP-UERJ \\ andrelinocampos@hotmail.com
}

Recebido em 04/01/2017 e aceito para publicação em 05/12/2017

DOI: $10.12957 /$ tamoios.2017.26834

O Observatório do Leste Metropolitano Rio de Janeiro (OBGEO-LMRJ) é um núcleo de pesquisa do Departamento de Geografia da Faculdade de Formação de Professores da Universidade do Estado do Rio de Janeiro - DGEO/FFP/UERJ, situado em São Gonçalo, município do leste da região metropolitana do Rio de Janeiro, com mais de 1.000.000 de habitantes, é o segundo maior do estado do Rio de Janeiro, sendo superado apenas pela Capital com mais seis um milhões de pessoas.

A FFP é a único campus de uma universidade pública, com ensino presencial, localizada no município de São Gonçalo atendndo cerca de 2500 alunos de graduação oriundos de inúmeros municípios da Região Metropolitana e do interior fluminense, inscritos em cursos de licenciatura em Pedagogia, História, Geografia, Matemática, Letras (Português/Literatura e Português/Inglês) e Biologia. Além de oferecer 9 (nove) cursos de pós-graduação (especialização), 6 (seis) a nível de mestrados - sendo 4 acadêmicos e 2 profissionais - e mais dois de doutoramentos (História Social e Educação).

Seu projeto político-pedagógico apoia-se na vinculação técnico científico sobre a realidade educacional, social, ambiental e cultural, sobretudo, no leste metropolitano do Rio de Janeiro. Além de oferecer seus espaços à população com inúmeras parcerias onde são realizados inúmeros eventos de cunho acadêmicos, como seminários, colóquios, seminários entre outras atividades de interesses para diferentes segmentos da sociedade gonçalense.

O corpo docente de alto nível acadêmico é comprometido com o desenvolvimento de projetos de pesquisa, bem como atividades de extensão. Possui 22 (vinte e dois) grupos de pesquisa reconhecidos pelo $\mathrm{CNPq}$, mais de 100 (cem) projetos de pesquisa apoiados por agências de fomento como a FAPERJ e CNPQ, dentre outras fontes. 
A FFP/UERJ vem se constituindo em referencia nacional na formação de professores no país, servindo de modelos para outras instituições, até mesmo do exterior, recebendo missões para compreender como funcionamos. E os alunos do DGEO, nos eventos acadêmicos, também se destacam servindo de exemplo de luta política e por suas pesquisas mostram a potencia de nosso departamento.

No que diz respeito ao Observatório do Leste Metropolitano Rio de Janeiro (OBGEO-LMRJ), ligado ao PPGG/DGEO/FFP, é a junção de quatro núcleos de pesquisas coordenados por docentes que são do DGEO/FFP que atuam nos programas, constituídos desta maneira:

- Núcleo de Pesquisa e Extensão Urbano, Território e Mudanças Contemporâneas (NUTEMC/DGEO/FFP), reconhecido pela UERJ/CNPq. Este grupo é percursor das pesquisas ligadas ao urbano no DGEO/FFP, no qual estão vinculados Professores doutores Andrelino Campos e Nilo Sérgio d'A. Modesto, coordenado pela Prof ${ }^{a}$ Dra. Catia Antonia da Silva (catia.antonia@gmail.com);

- Núcleo de Estudos Sociedade, Espaço e Raça (NoSER- DGEO-PPGG/FFP/UERJ) coordenado pelo Prof. Dr. Andrelino Campos (andrelinocampos@ hotmail.com);

- Núcleo Estudos de Cartografias Políticas, Sociais e Urbanas (NCPSU - DGEOPPGG/FFP/UERJ) coordenado pelo Prof. Dr. Nilo Sérgio d'Ávila Modesto (olingeo1@gmail.com)

- Núcleo de Estudos de Dinâmicas Ambientais e Geoprocessamento do Leste Metropolitano do Rio de Janeiro (DAG-LMRJ - - DGEO-PPGG/FFP/UERJ), coordenado pelo Prof. Dr. Vinicius da Silva Seabra (vinigeobr@gmail.com).

Para a concepção do OBGEO-LMRJ, acreditávamos que o município de São Gonçalo (sobretudo) e do Leste Metropolitano do Rio de Janeiro tinham poucos estudos que contemplassem os diferentes aspectos da vida coletiva nos recortes espaciais do urbano/regional. Neste sentido, os núcleos de pesquisas, acima referenciados, constituíram parcerias com alunos de graduação, ex-alunos que, mesmo depois de concluídas as suas licenciaturas, permaneceram frequentando os núcleos de pesquisas, e alunos que ingressaram nas pós-graduações, ajudaram a dar "sentido das coisas" do OBGEO-LMRJ.

Desta forma, é pretensão do OBGEO-LMRJ oferecer material sistematizado que ajudem a "desvendar" os municípios que compõem o leste metropolitano no que diz respeitos aos dados disponibilizados:

(a) Instituo Brasileiro de Geografia e Estatística (IBGE) no que diz respeito aos censos demográficos de 2000 e 2010;

(b) Instituto de Segurança Pública do Rio de Janeiro (ISP-RJ) desde 2002, atualizado mês a mês, até presente momento; 
Fará parte do conjunto de dados, enriquecendo ambas as fontes o material oferecido pela Federação das Indústrias do Rio de Janeiro (FIRJAN) que, de certa forma, complementam e atualizam os materiais oferecidos pelo IBGE.

A preocupação do OBGEO-LMRJ é trabalhar o urbano e o regional por meio da ferramenta de geoprocessamento, que se mostrou necessário pela falta de estudos sistematizados com os dados oriundos das instituições citadas acima.

O OBGEO-LMRJ foi criado em 2010 tendo como foco principal compreender as relações sócio-espaciais dos municípios e estabelecer comparações para traçar diagnósticos dos municípios, para os quais, de certa maneira, os dados da região são subsumidos pelos dados da capital, a cidade do Rio de Janeiro, e da Baixada Fluminense.

Assim, começamos a produzir uma série de artigos, monografia e algumas dissertações que estão em curso no ano de 2017 utilizando do material oferecido pelo OBGEO-LMRJ.

Entretanto, o que nos move, neste momento, que oficializamos a existência do OBGEO-LMRJ é a finalização do Atlas do Leste Metropolitano do Rio de Janeiro: Diagnóstico sócio-espacial dos municípios vistos pelo lado de cá da Baía de Guanabara que será disponibilizado até final de 2017. Acreditamos que deverá contribuir com professores da escola básica, pesquisadores e administração pública localizadas no LMRJ.

( $A$ UERJ (re)existe!) 